\title{
CHANGES IN LUNG FUNCTIONS OF AN INDIVIDUAL DURING HIS NORMAL SLEEPING BODY AND ARM POSITION COMPARED TO SUPINE POSITION
}

\author{
Pinto $M V G^{1}$, Kariyawasam $A^{2}$, Nandadeva TDP, Marasinghe IUK ${ }^{3}$, Amarasinghe $U^{4}$, \\ Jayakody $\mathrm{NS}^{4}$, Weerasinghe $\mathrm{WNL}^{4}$ \\ 1 Senior Lecturer, Dept of Anaesthesiology, ${ }^{3}$ Temporary Lecturer, Dept of Physiology, ${ }^{4}$ Temporary \\ Lecturer, Dept of Anaesthesiology, University of Peradeniya, SriLanka.
}

*Corresponding Author: vasantipinto@yahoo.com

\begin{abstract}
In normal people there are considerable inequalities of the ventilation and perfusion in the lung which can be further changed by position. Thus different V/Q mismatches will ultimately have an impact on arterial oxygenation. This study was designed to detect whether the lung functions are changed by adopting the patient's normal sleeping posture and the arm position during sleep.
\end{abstract}

The study was carried out as a prospective randomized study. The subjects suffering from asthma, COPD, acute lung infections or any chest deformity were excluded. Spontaneous Tidal Volume (STV), Forced Vital capacity (FVC), Inspiratory and Expiratory reserve volumes were measured in supine position and after adopting their normal sleeping posture with head and arm position.

Mean age, Height and Weight of the sample did not show a significant difference. Paired $t$ test was used to analyze the lung functions in all three positions. With regard to STV and FVC there is a significant difference of $p<0.05$ between supine position and after adopting the most comfortable sleeping position.

With the evidence of this study, lung functions are improved by adopting an individual's most comfortable sleeping position with arm position. This may be useful in clinical practice to improve oxygenation while ventilating patients.

In humans ventilation differs in different areas of the lung which can be further changed by body position $^{1 .}$ This is the same with perfusion. Thus different V/Q matches will ultimately have an impact on ultimate arterial oxygenation which can also be explained by physiological zones. Various observers have noted postural changes in certain lung volumes, such as vital capacity, expiratory reserve and functional residual capacity. ${ }^{2}$ Most of these studies have been carried out comparing lung functions in supine and sitting position.

An individual may adopt their most comfortable sleeping position with head and arm position in relation to the best locations of the most well ventilated areas of the lung, which may be contributing greatly to better oxygenation.
Our study aims to compare the lung functions in supine and normal comfortable sleeping position with head and arm positions.

Most popular sleeping positions:

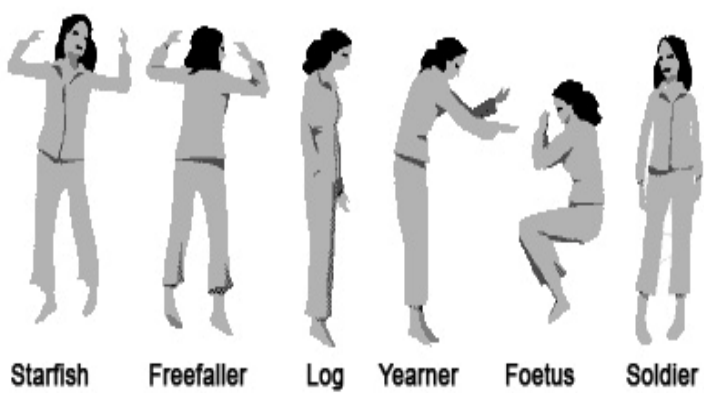

Figure 1: Sleeping Positions 
This study was designed to detect whether the lung functions are changed by adopting the patient's normal sleeping posture including the arm position during sleep.

\section{Materials and Methods}

The study was carried out as a prospective randomized study at the respiratory laboratory in the faculty of Medicine, Peradeniya. Ethics committee approval was obtained. 30 consented male medical students aged between 20 to $26 \mathrm{yrs}$ who are non smokers were selected for the study on random basis (Every $3^{\text {rd }}$ person entering the canteen during the time period of 10.00 am to 12.00 noon). The subjects suffering from asthma, COPD, acute lung infections, respiratory infections in the recent past, upper airway diseases or any chest deformity were excluded. Details with regard to age, gender, height, weight and their normal sleeping position with head and arm positions were documented by the investigator.

Spontaneous Tidal Volume (STV) and Forced Vital Capacity (FVC) were measured in the subjects using the electronic Spirometer in the two different postures; supine and after adopting their normal sleeping position with head and arm position. Each subject was kept in supine position for 5 minutes before recording their lung functions. At the end of the lung function assessment in supine position the subjects were asked to adopt their normal comfortable sleeping position for another 5 minutes at the end of which the same parameters were assessed. The data were analyzed by paired t test using SPSS statistical software $\left(13^{\text {th }}\right.$ version $)$.

\section{Results}

Mean age, Height, Weight and Body Mass Index (BMI) of sample did not show a significant difference and were $22 \mathrm{y}, 56.74 \mathrm{~kg}, 168.07 \mathrm{~cm}$ and $21.57 \mathrm{Kgm}^{-2}$ respectively. (Table 1)

Results were expressed as mean \pm Standard Deviation and the difference of mean values was considered significant when the obtained $\mathrm{p}$ value was $<0.05$
Table 1:

Demographic data

\begin{tabular}{|l|l|}
\hline & Mean \pm SD \\
\hline Age $($ Years $)$ & $22 \pm 1$ \\
\hline Body weight $(\mathrm{kg})$ & $56.74 \pm 9.12$ \\
\hline Height $(\mathrm{cm})$ & $168.07 \pm 5.65$ \\
\hline BMI $\left(\mathrm{kg} \mathrm{per} \mathrm{m}^{2}\right)$ & $21.57 \pm 2.43$ \\
\hline
\end{tabular}

The different sleeping positions observed in the subjects were supine with arms straight and flexed with internal rotation at elbows, prone with head turned laterally and arms flexed at elbows, right lateral and left lateral with arms straight and flexed with internal rotation at elbows and right lateral and left lateral recumbent. (Figure 1)

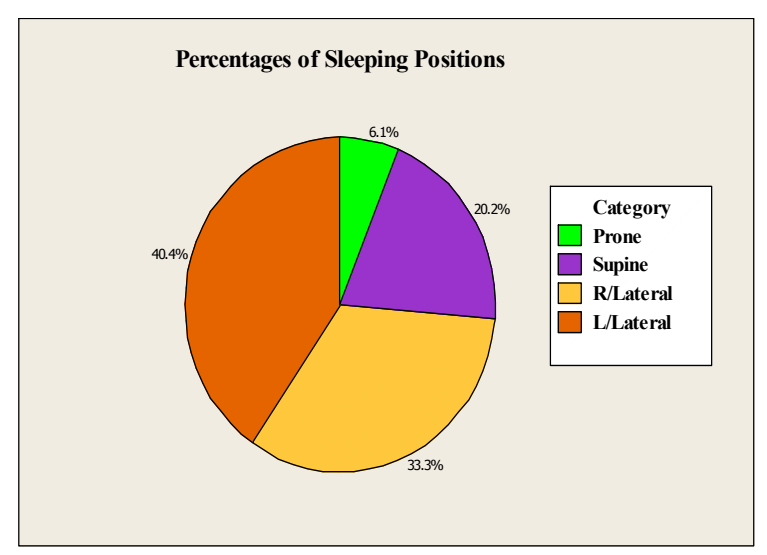

The mean STV was $0.5997 \mathrm{~L}$ in supine position where as in normal comfortable sleeping position and arm position it was increased to $0.7437 \mathrm{~L}$ (Table 2). There was a significant difference between the two positions with respect to STV at a significant level (alpha) of 0.000 .

\section{Table 2: Mean Spontaneous Tidal Volumes}

\begin{tabular}{|l|l|}
\hline Supine position & $0.5997 \mathrm{~L}$ \\
\hline $\begin{array}{l}\text { Comfortable sleeping } \\
\text { position }\end{array}$ & $0.7437 \mathrm{~L}$ \\
\hline
\end{tabular}

The FVC was increased from $3.621 \mathrm{~L}$ to $3.974 \mathrm{~L}$ when the subjects' position was changed from supine to normal comfortable sleeping position with arm position (Table 3). A significant difference of $p<0.05$ was evident between supine position and after adopting the most comfortable sleeping position in the same subject. 
Table 3: Mean Forced Vital Capacity

\begin{tabular}{|l|l|}
\hline Supine position & $3.621 \mathrm{~L}$ \\
\hline $\begin{array}{l}\text { Comfortable sleeping } \\
\text { position }\end{array}$ & $3.974 \mathrm{~L}$ \\
\hline
\end{tabular}

Our study results indicated that, adopting an individual's normal comfortable sleeping position with head and arm position there was an improvement in their lung volumes when compared to supine posture.

\section{Discussion}

Observers have noted postural changes in lung volumes such as, Vital Capacity (VC), Expiratory Reserve Volume (ERV) and Functional Residual Capacity (FRC). But most of these studies have been carried out in supine and sitting position.

Literature shows that a change in posture from sitting to horizontal position causes a decrease in effort dependent inspiratory and expiratory flow rates $^{3}$. This may be due to the fact that in normal awake subjects oro-pharyngeal passage of airways has a smaller diameter in lying than in sitting posture. Thus the change in effort dependent maximum inspiratory and expiratory flow rates could be due to the increase in the resistance of upper airways on assuming horizontal postures. No change of airway resistance was shown to occur in supine as compared to lateral lying position. Oxygen saturation and FRC were found to be significantly higher in the prone position ${ }^{4}$ .This increase in FRC in the prone position can be explained by the alteration in diaphragmatic mechanics (Lap Hace Law), improved drainage of secretions and reduction of intra pulmonary shunting. A number of investigators have examined pulmonary mechanics in the prone and supine positions. However these studies have largely been carried out in spontaneously breathing neonates with mild lung disease.
The location of the highly or less ventilated areas of the lung can be contributing greatly to the oxygenation. Identifying these areas in each individual may be difficult needing sophisticated lung function tests. Adopting their comfortable sleeping position with arm position clearly showed an improvement of their lung volumes. This can be studied further and applied to patients with respiratory compromise as well.

\section{Conclusion:}

With the evidence of this study, it shows that lung functions are improved by adopting an individual's most comfortable sleeping position with arm position. This can be used in clinical practice to improve oxygenation while ventilating patients.

\section{Acknowledgement}

The authors gratefully acknowledge the support of the staff at the Department of Physiology, Faculty of Medicine, Peradeniya and the medical students who took part in the study for their valuable support and participation.

\section{References:}

1. Manning F, Dean E, Ross J, Abboud RT. Effects of Side Lying on Lung Function in Older Individuals. Physical therapy. 1999; 79(5):456-66.

2. Fowler W S. Lung function studies. IV. Postural changes in respiratory dead space and functional residual capacity. 1950; J Clin Invest. 1950; 29(11):1437-1438.

3. Talwar A, Sood, S, Sethi J. Effect of body posture on dynamic lung functions in young non-obese Indian subjects. Indian Journal of Medical Sciences. 2002; 56 (12): 607-12.

4. Bhat RY et al. Effect of Posture on Oxygenation, Lung Volume, and Respiratory Mechanics in Premature Infants Studied Before Discharge. Pediatrics in Review. 2003; 112 (1): 29-32. 